\title{
Organ Culture as a Useful Method for Studying the Biology of Blood Vessels and Other Smooth Muscle Tissues
}

\author{
Hiroshi Ozaki* and Hideaki Karaki \\ Department of Veterinary Pharmacology, Graduate School of Agriculture and Life Sciences, The University of Tokyo, \\ Bunkyo-ku, Tokyo 113-8657, Japan
}

Received February 18, 2002

\begin{abstract}
The benefit of organ culture is to retain the original structural relationship between various cell species and their interactions and enable us to study the long-term effects of exogenous stimuli. Organ culture methods have been used especially in the studies of the proliferative vascular diseases, such as atherosclerosis and restenosis. We describe here that organ culture is a useful in vitro method to study the biology of vascular and other smooth muscle organs.
\end{abstract}

Keywords: Organ culture, Smooth muscle, Endothelium, Proliferation, Growth factor

\section{Introduction}

In the pathophysiological studies on blood vessels, longterm effects of pathogenic and therapeutic agents have usually been examined using both in vivo and in vitro studies. The advantages of the in vivo whole body study is to represent real pathological features, while the disadvantage is that it is difficult to control experimental conditions. On the other hand, in the in vitro studies using cultures of dispersed smooth muscle cells, it is easy to control the experimental conditions.

Modulation of vascular cell type depends on growth factors and is influenced by cell-to-cell and cell-to-matrix interactions. An organ culture system has the distinct advantages of better preservation of tissue architecture, cell-to-cell interactions, extracellular matrix and cell morphology and function. Thus, the organ culture study has several advantages over the above-mentioned classical, in vivo and in vitro methodologies.

In this review, we describe that organ culture is a useful method for analyzing the long-term effects of various pharmacological agents on vasculature and basic vascular biology. We further introduce organ culture studies on other types of smooth muscle tissues.

*Corresponding author. FAX: +81-3-5841-8183

E-mail: aozaki@mail.ecc.u-tokyo.ac.jp
2. Proliferative changes in the vascular smooth muscle 2-1. Serum-free condition

Cultured smooth muscle cells are known to rapidly change from the contractile to the synthetic cellular phenotype. These changes that occur in the cells complicate the interpretation of data obtained in the in vitro studies. In a cell culture study, the dispersed cells are usually incubated with fetal bovine serum (FBS) that contains various growth factors and other unidentified biological factors, to stimulate cell differentiation and growth, and to increase cell viability. In organ culture studies, however, this can create problems when assessing the growth-related reactions. Indeed, culture of vascular tissue in minimum essential medium (MEM) with FBS usually inhibits smooth muscle contractility (see below). To overcome this problem, we usually use a serum-free culture as a control. Unfortunately, after incubation of tissue in a serum-free condition for several days, the vascular tissues usually change their contractile functions compared with fresh tissue.

In the rabbit mesenteric artery, although the amplitude of contraction induced by high $\mathrm{K}^{+}$was not changed after organ culture in serum-free medium for a week, the concentration-response curve shifted to the left compared with that in the fresh arteries (1). The maximal contractile force due to norepinephrine, on the other hand, was reduced and the concentration-response curve shifted to the left in the serum-free arteries. A decrease in smooth muscle contractility has also been observed in the rat aorta after serum-free culture (2). In organ cultured porcine coronary artery, on 
the other hand, tension development to endothelin-1 was somewhat increased compared with fresh vessels (3). In human temporal artery (4), the contractile activity due to activation of the endothelin B receptor was increased after organ culture for 4 days. All these data suggest that compared with fresh vessels, contractile activity changes even after simple cultivation with essential culture medium, and the features of the changes are variable depending on the tissue species. Therefore, organ culture has its limitations to keep the native contractile activity of smooth muscle cells.

Then a question arises on the cause of the changes induced by the serum-free culture. An interesting finding of the study by Wright et al. (2) is that the supplementation of retinoic acid, one of the nuclear receptor ligands that causes a wide variety of developmental changes, returned the response of rat aorta almost to normal. Similarly, Xue et al. (5) have reported that the decrease in normal contractility of organ-cultured mesenteric resistance arteries was prevented by another ligand of the nuclear receptor $1 \alpha, 25$ dihydroxyvitamin $D_{3}$. Ishibashi and Bukoski (6) further examined the change in myosin isoform content in the mesenteric artery, indicating that the shift of myosin isoform expression correlates with the decrease in active stress, and this was reversed by $1 \alpha, 25$-dihydroxyvitamin $D_{3}$. These results suggest that circulating nuclear receptor ligands, such as retinoic acid and 1 $\alpha, 25$-dihydroxyvitamin $\mathrm{D}_{3}$, may be necessary for the maintenance of contractile function of aortic smooth muscle in the tissue culture condition.

\section{2-2. Fetal bovine serum}

Pathological conditions such as hypertension, atherosclerosis and diabetes are often associated with proliferation and differentiation of vascular smooth muscle cells and subsequent structural changes in the vascular wall. Under these conditions, various types of autocrine and paracrine growth factors produced by the vascular walls, rather than a single factor, act to modify the smooth muscle cell growth through a network of cellular interactions (7). The expression of numerous tissue-specific functions is also known to be modulated according to the status of cell growth. Thus, it may be possible that growth factors alter not only the morphology but also the functions of smooth muscle under vascular proliferative conditions. However, the relationship between the morphological and the functional changes induced by growth stimulation in vascular tissue remains to be clarified. To evaluate possible roles of growth stimulation on the vascular wall, many studies have examined the effects of chronic treatments of vascular tissue with FBS, an unspecified mixed source of various growth factors, on both the morphology and function of smooth muscle using an organ culture system.

The morphological and functional changes in rabbit mesenteric arterial tissue cultured with FBS have been carefully studied by Yamawaki et al. (1). In the medial layer of the arteries cultured with FBS for a week, apparent morphological signs of proliferation, disorientation and death of smooth muscle cells were observed. In the FBStreated arteries, both the amplitude of contractions induced by high $\mathrm{K}^{+}$and norepinephrine and the sensitivity to these stimulants were significantly reduced compared with those of the serum-free arteries. In the permeabilized arteries, the amplitude of $\mathrm{Ca}^{2+}$-induced contraction and the sensitivity of the contractile apparatus to $\mathrm{Ca}^{2+}$ were reduced after FBS-treatment. These results suggest that chronic FBS-treatment of rabbit mesenteric arteries impairs muscle contractility by inducing the morphological and phenotypic changes in smooth muscle cells. Voisard et al. (8), on the other hand, explored the organ culture with FBS for experimental models of restenosis. After the treatment of renal arteries with FBS for up to 3 weeks, bromodeoxyuridine (BrdU)-positive cells were detected in the neointima, indicating mitotic activity in this area. After 3-8 weeks, a clear increase of neointimal thickening was found. Their data emphasized the importance of the role of growth factors proliferative response of smooth muscle, and this model offers very useful opportunities for in vitro investigations of proliferative vascular disease.

\section{2-3. Other proliferative agents}

Platelet-derived growth factor (PDGF) is a potent vascular smooth muscle cell mitogen and chemoattractant and considered to play a major role in the various vascular proliferative diseases. The role of PDGF in neointima formation has been examined using human saphenous vein organ culture (9). The expression of PDGF mRNA was low in veins before culture. A neointima consisting of densely packed smooth muscle developed after 2 weeks of culture with FBS. The dense packing and high expression of PDGF mRNA in neointimal smooth muscle led to higher PDGF protein concentrations in the neointima. The anti-PDGF antibodies significantly reduced neointimal thickness and the number of neointimal cells. These results suggest that PDGF plays an essential role in migration of smooth muscle into the neointima.

Angiotensin II is known to stimulate growth of vascular smooth muscle cells, and it is assumed to influence neointimal proliferation during restenosis in response to vascular injury. This assumption has been confirmed by organ culture studies using porcine coronary artery. Incubation of porcine coronary artery segments with FBS in vitro results in the development of a neointima associated with a compact extracellular matrix and few disruptions in the internal elastic lamina (10). In this organ culture model of coronary restenosis, because the inhibition of angiotensin II receptors effectively inhibits cell proliferation and restenosis 
post-angioplasty in vitro, it is suggested that angiotensin II contributes to neointimal proliferation and validates the concept that receptor antagonists could contribute to the therapeutic management of restenosis. Among the studies using organ culture, the saphenous vein has been frequently used because excessive smooth muscle cell proliferation is a feature of intimal hyperplasia, the pathological lesion of vein graft stenosis. Ibrahim et al. (11) further examined the effect of angiotensin II on DNA synthesis of human saphenous vein in organ culture. After 7-day exposure to medium containing FBS plus angiotensin II, there was a marked increase in DNA synthesis. The effect of angiotensin II was comparable to that of PDGF.

Like angiotensin II, endothelin-1 is a potent mitogen for vascular smooth muscle cells, and the effects of this compound on vascular remodeling have been tested in an organ culture study of the saphenous vein. Masood et al. (12) found that addition of endothelin-1 to saphenous vein culture caused a significant increase in median neointimal thickness, suggesting that endothelin-1 is a mediator of intimal hyperplasia in human saphenous vein in vitro and that endothelin receptor antagonists may therefore be of therapeutic value in the modulation of vein graft intimal hyperplasia.

\section{Role of vascular endothelium}

One of the advantages of organ culture study over those of dispersed cells in in vitro study is that we could observe the cell-to-cell interactions such as those between endothelial cells and smooth muscle cells under a physiological condition.

The role of the presence of endothelium has been examined in organ-cultured vessels (13). It was found that rat aorta without the endothelium failed to constrict in response to phenylephrine after 24-h culture, whereas in the aorta with endothelium, there was a normal constrictor response. The constrictor activity in cultured aortas was restored by concomitant treatment with either the protein synthesis inhibitor cycloheximide or a nitric oxide synthase (NOS) inhibitor. Thus some of the immediate effects of endothelium removal involve intrinsic mechanisms resulting in inducible NOS (iNOS) synthesis, which leads to NO-dependent tissue damage and loss of contractile function.

The neointimal formation is observed in a porcine aortic organ culture model that exhibits intimal smooth muscle cell accumulation after a brief culture (14). This in vitro change is dependent upon an intact endothelium, as removal of the endothelium at the time of harvesting results in failure to develop neointima. The data further indicated that, in the presence of the endothelium, the neointimal formation may be mediated by upregulation of fibroblast growth factor (FGF) receptor-1 in the intimal cells.
Although the primary target of PDGF has been considered to be vascular smooth muscle cells, the effects may be at least partly due to the chronic effect on vascular endothelium. Yamawaki et al. (15) have examined the effects of chronic treatment with PDGF on the function of vascular endothelium. Culture of rabbit mesenteric arteries with PDGF for 1 week decreased the relaxant effect of substance $\mathrm{P}$ and ionomycin, NO production, and endothelial NOS (eNOS) mRNA level, whereas the sodium nitroprussideinduced relaxation did not change. These results suggest that PDGF has a chronic effect on vascular endothelium to decrease eNOS mRNA and NO production and to impair NO-dependent and endothelium-dependent relaxation. The effects of PDGF to impair eNOS mRNA might be responsible not only for changes in vascular tone but also for the progression of the disease process.

It has been reported that in pulmonary arteries isolated from patients with pulmonary hypertension due to chronic obstructive lung disease, the release of NO from the endothelium is impaired $(16,17)$. Additionally, chronic hypoxia-induced pulmonary hypertensive rats exhibit a decrease in endothelium-dependent relaxation of pulmonary arteries (18). Murata et al. (19) have examined the effects of chronic hypoxic stress in an organ culture study to solve the mechanism of hypoxia-induced endothelium dysfunction. In intrapulmonary arteries cultured under hypoxic conditions $\left(5 \% \mathrm{O}_{2}\right)$ for 7 days, endothelium-dependent relaxation and cGMP accumulation induced by substance $\mathrm{P}$ were decreased as compared to those of a normoxic control $(20 \%$ $\mathrm{O}_{2}$ ). Hypoxia did not change the eNOS mRNA expression, the eNOS protein expression or the expression of eNOS regulatory protein, caveolin-1. Morphological study revealed atrophy of the endothelial cells and condensation of the eNOS protein in many cells. These results suggest that chronic hypoxia impairs NO-mediated arterial relaxation without changing either the eNOS protein expression or the NO-sensitivity of smooth muscle cells in pulmonary arteries.

\section{Gene transfer}

Gene transfer to blood vessel is a promising new approach in the treatment of vascular diseases. The organ culture method has been widely used for testing the virus vectors for cardiovascular gene therapy. Furthermore, organ culture study also provides the basis for application of the antisense technique to knockout specific regulatory proteins. One advantage of the organ culture method is that we can test the contractility of the smooth muscle cells following the gene transfection.

Various adenovirus vectors have been tested using organ cultures derived from different vascular origins, such as the saphenous vein, iliac artery, left internal mammary artery and aorta, and from different species using luciferase, 
LacZ, or green fluorescent protein (GFP) marker gene expression (20). The authors concluded that an Ad5-based virus carrying the fiber of Ad16 is a potent vector for the transduction of primate cardiovascular cells and tissues.

Adenovirus containing LacZ or luciferase gene has been used to test the efficiency of gene transfer into various vascular tissues. Yao and Wang (21) compared the difference in the thoracic aorta and renal artery of rat. The efficiency of the transfection was greater in the renal artery than the thoracic aorta. To determine whether the increased efficiency of adenovirus-mediated gene transfer into renal artery is a function of the replication status of vessels, the authors assessed ${ }^{3} \mathrm{H}$-thymidine incorporation, which indicated that more proliferating cells are present in the renal artery than the thoracic aorta and confirmed that the efficiency of adenovirus-mediated gene transfer into cells is related to the degree of proliferative activity.

Rekhter et al. (22) have introduced an adenovirus vector encoding a marker gene, alkaline phosphatase, into human vessels, such as the internal mammary arteries, saphenous veins, and coronary arteries in organ culture. In the vessels, the recombinant gene was expressed preferentially in the endothelial cells and it was very feasible in intimal smooth muscle cells. The important findings of their study was that a treatment with collagenase and elastase increased the percentage of transgenic alkaline phosphatase-positive cells, suggesting that the pattern of gene expression was affected by the amount of surrounding extracellular matrix.

Extracellular matrix remodeling by metalloproteinase enzymes is an essential component of neointimal formation. Thus, metalloproteinase is a potential target for localized gene therapy. To evaluate this concept, George et al. $(23,24)$ tested the effect of adenovirus-mediated gene transfer of tissue inhibitor of metalloproteinase. Incubating the veins with the adenovirus led to the expression of tissue inhibitor of metalloproteinase in surface cells and inhibited neointimal formation and smooth muscle migration. They concluded that metalloproteinase overexpression reduces neointimal thickening, primarily by inhibiting metalloproteinase activity and hence smooth muscle cell migration.

Increased elastase activity and deposition of the matrix glycoprotein, tenascin-C, codistributing with proliferating smooth muscle cells, are the features of pulmonary vascular disease. In cultured smooth muscle cells, tenascin-C is induced by matrix metalloproteinases and amplifies the proliferative response to growth factors. Conversely, suppression of tenascin-C leads to smooth muscle cell apoptosis. It has been reported that hypertrophied rat pulmonary arteries in organ culture, which progressively thicken in association with cell proliferation and matrix accumulation, can be made to regress by inhibiting either serine elastases or metalloproteinases (25). This effect is associated with reduced tenascin-C, suppression of smooth muscle cell pro- liferation, and induction of apoptosis. Selective repression of tenascin- $\mathrm{C}$ by transfecting the pulmonary arteries with antisense also induces smooth muscle cell apoptosis and arrests progressive vascular thickening. The authors suggested that proteinase inhibition is a novel strategy to induce regression of vascular proliferative disease. Cowan et al. (26) further reported that elastase inhibitors can reverse advanced pulmonary vascular disease produced in rats by injecting monocrotaline, an endothelial toxin.

Endothelium-dependent relaxation cannot be fully attributed to the release of nitric oxide or prostacyclin. In resistance-sized vessels and coronary arteries, a high proportion of endothelium-dependent relaxation can be attributed to the release of endothelium-derived hyperpolarizing factor (EDHF). The data of Fisslthaler et al. (27) are consistent with the hypothesis that a cytochrome P450-derived epoxide, namely 11,12-epoxyyeicosatrienoic acid, is an EDHF. Using an organ culture technique, Bolz et al. (28) have examined the antisense oligonucleotide transfection to determine whether the EDHF is a cytochrome P450-related compound or not. Isolated resistance arteries from hamster gracilis muscle were perfused and exposed to antisense oligonucleotides against the coding region of CYP2C8/9, an isoform expressed in endothelial cells. After the treatment, the EDHF-mediated responses were markedly attenuated and the antisense was specifically targeted to the endothelial layer as assessed by confocal microscopy. They concluded that a CYP2C8/9-related isoform functions as an EDHF synthase in the hamster resistance arteries.

h-Caldesmon is a thin-filament-associated protein believed to be important in the regulation of smooth muscle contraction, although the precise mechanism is unknown. Earley et al. (29) used antisense oligonucleotides to produce intact swine carotid smooth muscle tissue deficient in h-caldesmon. The h-caldesmon content was decreased by approximately $80 \%$ after 7 days in culture with antisense oligonucleotides. Antisense oligonucleotides produced a significant decrease in the h-caldesmon/actin ratio, and h-caldesmon-deficient tissues produced less force than controls.

h1-Calponin is another smooth muscle actin binding protein that is thought to be an important regulator of the smooth muscle contraction $(30,31)$. Je et al. (32) also used oligonucleotides to deplete h1-calponin in vascular tissue. They employed the organ culture in combination with the transient permeabilization method to efficiently incorporate the oligonucleotide into cells. Treatment of ferret aorta with h-calponin antisense oligonucleotides resulted in a decrease in protein level to $54 \%$. Contraction in response to phenylephrine, but not high $\mathrm{K}^{+}$, was significantly decreased in the antisense-treated muscles, suggesting that calponin plays a significant role in the regulation of $\mathrm{Ca}^{2+}$ sensitivity of smooth muscle contractile element. 
The same protocol has been applied to focal adhesion kinase (FAK) (33). FAK has been implicated in signaling pathways that regulate cytoskeletal organization, and it has been shown to be involved in cell motility and the spreading of cultured cells. FAK is phosphorylated on tyrosine residues during the contractile activation of the tracheal smooth muscle tissues with muscarinic agonists (34). The authors further hypothesized that FAK may play an important role in smooth muscle contraction and used antisense oligodeoxynucleotides to produce intact airway tissue deficient in FAK. Antisense decreased FAK expression, and increases in force, intracellular $\mathrm{Ca}^{2+}$ level and myosin light chain phosphorylation in response to stimulants were depressed in the FAK-depleted tissues. The tyrosine phosphorylation of paxillin, a substrate for FAK, was also significantly reduced in FAK-depleted strips. These results suggest that FAK plays a role in regulating intracellular free $\mathrm{Ca}^{2+}$ concentration and myosin light chain phospholyration.

\section{Mechanical stress}

Prolonged elevated blood pressure results in vascular remodeling, characterized by increased vessel wall thickness, vascular smooth muscle hypertrophy and/or hyperplasia, and accumulation of extracellular matrix $(35-37)$. However, the precise mechanisms controlling these processes remain to be elucidated, and cell culture study is not suitable for the resolution.

Among the physiological factors, different forms of mechanical stimulation are constantly acting on the vessel wall, but organ-cultured vascular tissue is usually free from such mechanical stresses. Birukov et al. (38) have examined the effects of mechanical factors, in the form of circumferential stress and shear stress, on the characteristics of the smooth muscle contractile phenotype in an organ culture of rabbit aorta. In the nonpressurized vessel without endothelium, h-caldesmon and filamin contents decreased, while the application of intralumininal pressure to aortic segments prevented such decreases. Maintenance of hcaldesmon and filamin levels in organ cultures of pressurized and stretched vessels demonstrates the positive role of mechanical factors in the control of the vascular smooth muscle differentiated phenotype.

Extracellular signal-regulated kinase (ERK) $1 / 2$ are regulatory kinases convergent for signals transduced by many pathways, and they participate in the control of gene expression. ERK $1 / 2$ have been reported to be transiently activated by stretching vascular smooth muscle cells (39). Using an organ culture model of rabbit aorta, Birukov et al. (40) studied short- and long-term ERK1/2 activation by intraluminal pressure in the arterial wall. They demonstrated a sustained activation of ERK $1 / 2$ and tyrosine kinases by the intraluminal pressure. Pressure-induced
ERK1/2 activation has also been proven to be Src-family tyrosine kinase-dependent.

Zeidan et al. (41) have also used organ culture to investigate mechanisms involved in adaptation to mechanical load. It was found that length-force relations were shifted toward longer length in stretched cultured veins compared with freshly dissected veins, whereas the length-force relations of unstretched cultured veins were shifted in the opposite direction. Electron microscopy revealed increased cell cross-sectional area in stretched veins, and protein contents were greater. The results demonstrated that smooth muscle cells respond to stretch with a physiological adaptation involving hypertrophy/hyperplasia and remodeling of the contractile system in an organ culture study.

\section{Pathophysiological and toxicological approaches}

The organ culture method is also suitable for studying the chronic effects of various pathophysiological and toxicological related agents.

During inflammatory conditions, the underlying smooth muscle acquires the ability to release NO and prostaglandins. An organ culture study enables us to study inflammatory responses of vascular tissues without a participation in the infiltration of circulatory immune cells. BishopBailey et al. (42) investigated the induction of iNOS and cyclooxygenase (COX)-2 by bacterial lipopolysaccharide (LPS) in organ cultured rat aorta. Treatment with LPS increased the release of prostaglandins and NO, an effect that was inhibited by protein synthesis inhibitor cycloheximide, the anti-inflammatory steroid dexamethasone, and the nonsteroidal anti-inflammatory drug indomethacin. There was also an apparent increase in the level of mRNAs for iNOS and COX-2.

Hori et al. (43) investigated the effects of LPS on the induction of iNOS and COX-2 in muscularis-resident macrophages of rat intestine. When the tissue was incubated with LPS for $4 \mathrm{~h}$, the mRNA levels of iNOS and COX-2 were increased. The majority of iNOS and COX-2 proteins appeared to be localized to the dense network of muscularis-resident macrophages immunoreactive to ED2. The increased expression of iNOS mRNA by LPS was suppressed by indomethacin but not by $N^{\mathrm{G}}$-monomethyl-Larginine (L-NMMA). The increased expression of COX-2 mRNA by LPS was affected neither by indomethacin nor by L-NMMA. Muscle contractility stimulated by carbachol was significantly inhibited in the LPS-treated muscle, which was restored by treatment of the tissue with LNMMA and indomethacin. They concluded that LPSinduced iNOS gene expression is mediated by autocrine regulation of prostaglandins through the induction of COX2 gene expression.

Stimulation of vascular smooth muscle by LPS has been shown to produce interleukin- $1 \beta$ and to induce vasodilata- 
tion in septic shock. To understand the mechanisms of interleukin- $\beta$ induced vascular relaxation, Takizawa et al. (44) examined the chronic effects of interleukin- $1 \beta$ on contractility and cyclic GMP contents of vascular smooth muscle. After treatment of the rat aorta with interleukin- $1 \beta$ for $6 \mathrm{~h}$, the cyclic GMP content increased and the contraction induced by the $\alpha_{1}$-agonist phenylephrine was partially inhibited. Consistent with the above-mentioned paper (42), an inhibitor of NO synthase prevented the inhibitory effect of interleukin- $\beta$. After treatment with interleukin- $1 \beta$ for $24 \mathrm{~h}$, on the other hand, the phenylephrine-induced contraction was inhibited more strongly, and, under this condition, NO inhibitor did not reverse the inhibition. In the presence of excess $\mathrm{KCl}$ or the non-selective $\mathrm{K}^{+}$channel inhibitor tetraethylammonium, the inhibitory effect of the 24-h interleukin- $1 \beta$ treatment on phenylephrine-induced contraction was restored. These results suggest that interleukin- $1 \beta$ inhibits vascular smooth muscle contraction by time-dependent and dual mechanisms: activation of the $\mathrm{NO} /$ cyclic GMP system and membrane hyperpolarization. Kauser et al. (45) confirmed the above findings that the treatment of the rat aortic tissue with interleukin- $\beta$ for $12 \mathrm{~h}$ led to the expression of iNOS mRNA and protein.

While estrogen is known to prevent the development of atherosclerosis, the mechanism is not completely understood. The effect of estrogen on eNOS has been investigated in an organ culture study (46). Preincubation with a physiological concentration of $17 \beta$-estradiol over $8 \mathrm{~h}$ significantly enhanced the activity of eNOS in the cultured human umbilical vein and bovine aortas, confirming the anti-atherosclerotic effect of estradiol. On the other hand, 24-h in vitro treatment with estradiol in an organ culture system attenuated the phenylephrine-induced contraction in endothelium-denuded aortas, and this effect was inhibited by the NOS inhibitor (47). They suggested that estradiol can attenuate the vasoconstriction by a process that involves sustained induction of iNOS in nonendothelial cells. Kauser et al. (45) reported, however, that $17 \beta$-estradiol inhibited the lnterleukin- $1 \beta$ induced nitrite accumulation and iNOS mRNA expression and restored the reduced phenylephrine-induced contraction.

Organ culture can also be used for toxicological studies. Murata et al. (48) investigated the chronic effects of doxorubicin, a commonly used anticancer agent, on morphological and functional changes in the rabbit mesenteric artery using an organ culture system. In arteries cultured with a low concentration $(0.3 \mu \mathrm{M})$ of doxorubicin, considered a therapeutic concentration, for 7 days, the contractions induced by norepinephrine, but not those induced by endothelin-1 or high $\mathrm{K}^{+}$, were strongly inhibited. This reaction was followed by a decrease in the induction of the $\alpha_{1 \mathrm{~A}}$-adrenoceptor protein without any change in the mRNA level. In the arteries cultured with a higher concen- tration $(1 \mu \mathrm{M})$ of doxorubicin for 7 days, contractions induced by endothelin- 1 or high $\mathrm{K}^{+}$and absolute force in the permeabilized muscles were also inhibited. Morphological examinations revealed the existence of concentrated nuclei and TUNEL-positive smooth muscle cells, and internucleosomal DNA fragmentation was also detected, indicating the induction of apoptosis. Murata et al. (49) also attempted to determine the chronic effects of doxorubicin on vascular endothelium using an organ culture system. In rabbit mesenteric arteries treated with $0.3 \mu \mathrm{M}$ doxorubicin for 1 week, DNA damage and apoptosis occurred. In arteries treated with a higher concentration $(1 \mu \mathrm{M})$ of doxorubicin, apoptosis and damage to nuclei occurred in the endothelial cells 3 days after treatment, and detachment and excoriation of endothelium from the tunica interna of the vascular wall were also observed.

\section{Smooth muscle other than the vascular tissue}

The organ culture technique has also been applied to smooth muscle tissues other than vascular tissue. Work has been done primarily in gastrointestinal and airway tissues, especially for the purpose of understanding the developmental biology.

Intestinal muscular wall is composed of multiple cell types. Interstitial cells of Cajal (ICCs) have been identified as pacemaker cells in the gastrointestinal tracts of vertebrates. Development of ICCs requires signaling via Kit receptors. Ward et al. (50) have studied the development of ICCs in pacemaker regions and the onset of electrical rhythmicity in the small bowel and proximal colon of the mouse. ICCs and rhythmicity developed in an apparently normal manner in tissues isolated at birth and placed in organ culture. Treatment of small intestinal tissues taken from embryos with neutralizing c-Kit antibodies abolished ICCs development and the organization of ICCs into networks that typically occurs during the late embryonic period. Treatment of muscles taken from newborn animals with c-Kit antibodies blocked postnatal development of ICCs, disrupting already established and functional ICCs networks. These results suggest that ICCs networks develop before birth.

The epidermal growth factor (EGF) receptor-knockout mouse that was reported by Miettinen et al. (51) exhibits delayed maturation of the intestinal epithelium compared with control mouse and has abnormally shortened small intestinal villi and flattened colonic mucosa. This suggests that EGF signaling plays important roles in embryonic gut development, and Duh et al. (52) further elucidated these findings in an organ culture study. During the organ culture, control specimens grew in length, developed smooth muscle, simple columnar epithelial and goblet cell phenotypes, showed early villus formation in the proximal intestine, and increased expression of villin and intestinal fatty 
acid binding protein mRNA. Addition of EGF also inhibited colonic length growth.

Nonadrenergic, noncholinergic (NANC) relaxations of airway smooth muscle are thought to be mediated by vasoactive intestinal polypeptide (VIP) and NO. Previous studies of guinea pig trachea suggest that the ganglion neurons mediating NANC relaxations, but not cholinergic contractions, are associated with the esophagus. Canning et al. (53) explored this hypothesis using tracheas maintained in organ culture for 2 days with or without intact adjacent esophagus. With the esophagus, the cultured tissue displayed cholinergic contractions and NANC relaxations to electrical field stimulation, and VIP and NOS nerve fiber densities were similar to those of control tracheas. By contrast, without the esophagus, NANC relaxations to field stimulation were not observed, and VIP and NOS nerve fiber densities were reduced. These results provide evidence that NANC relaxations are mediated by VIP and NO co-released from noncholinergic parasympathetic nerve endings derived from neurons intrinsic to the esophagus.

\section{Conclusion}

The medical database indicates that, in the field of vascular biology, prior to December 2001, more than two hundred papers had been published in which the organ culture method was used with the number of papers beginning to grow in the mid nineties. This seems to coincide with the growing awareness of proliferative vascular diseases. The organ culture method has many advantages over the cell culture and whole body studies. In particular, with molecular tools that allow manipulation of specific signal transudation molecules, this method will provide a better understanding of smooth muscle biology in which multiple types of cells are present and interacting with each other. In addition, this technique allows us simple and rapid evaluation of morphological and functional changes which could be used for high-throughput screening of pharmacological agents. The organ culture method may bridge the gap between in vitro cell culture studies and in vivo whole body studies.

\section{Acknowledgments}

This work was partly supported by Grants-in-Aid for Scientific Research from Ministry of Education, Culture, Sports, Science and Technology, Japan and Japan Society for the Promotion of Sciences, Japan and a Program for Promotion of Basic Research Activities for Innovative Biosciences (BRAIN).

\section{REFERENCES}

1 Yamawaki H, Sato K, Hori M, Ozaki H, Nakamura S, Nakayama $\mathrm{H}$, Doi K and Karaki H: Morphological and functional changes of rabbit mesenteric artery cultured with fetal bovine serum. Life Sci 67, 807 - 820 (2000)

2 Wright G, Wang S, Bailey G, Reichenbecher V and Wright GL:
Effect of retinoic acid on contractile competence of vascular smooth muscle. Am J Physiol 270, H1363 - H1370 (1996)

3 Hill BJ, Katwa LC, Wamhoff BR and Sturek M: Enhanced endothelin A receptor-mediated calcium mobilization and contraction in organ cultured porcine coronary arteries. J Pharmacol Exp Ther 295, $484-491$ (2000)

4 White LR, Leseth KH, Juul R, Adner M, Cappelen J, Aasly J and Edvinsson L: Increased endothelin $\mathrm{ET}_{\mathrm{B}}$ contractile activity in cultured segments of human temporal artery. Acta Physiol Scand 164, 21 - 27 (1998)

5 Xue $\mathrm{H}$, McCarron DA and Bukoski RD: 1,25 $(\mathrm{OH})_{2}$ vitamin $\mathrm{D}_{3}$ attenuates the loss of resistance artery contractile function associated with incubation in culture media. Biochem Biophys Res Commun 174, 11 - 17 (1991)

6 Ishibashi K and Bukoski RD: Myosin isoform expression and force generation in cultured resistance arteries. Am J Physiol 272, C1144 - C1150 (1997)

7 Ross R: The pathogenesis of atherosclerosis: a perspective for the 1990s. Nature 362, $801-809$ (1993)

8 Voisard R, von Eicken J, Baur R, Gschwend JE, Wenderoth U, Kleinschmidt K, Hombach V and Hoher M: A human arterial organ culture model of postangioplasty restenosis: results up to 56 days after ballooning. Atherosclerosis 144, 123 - 134 (1999)

9 George SJ, Williams A and Newby AC: An essential role for platelet-derived growth factor in neointima formation in human saphenous vein in vitro. Atherosclerosis 120, 227 - 240 (1996)

10 Wilson DP, Saward L, Zahradka P and Cheung PK: Angiotensin II receptor antagonists prevent neointimal proliferation in a porcine coronary artery organ culture model. Cardiovasc Res 42, 761 - 772 (1999)

11 Ibrahim J, Hughes AD and Sever PS: Action of angiotensin II on DNA synthesis by human saphenous vein in organ culture. Hypertension 36, 917 - 921 (2000)

12 Masood I, Porter KE and London NJ: Endothelin-1 is a mediator of intimal hyperplasia in organ culture of human saphenous vein. Br J Surg 84, 499 - 503 (1997)

13 Binko J, Meachem S and Majewski H: Endothelium removal induces iNOS in rat aorta in organ culture, leading to tissue damage. Am J Physiol 276, E125 - E134 (1999)

14 Daley SJ and Gotlieb AI: Fibroblast growth factor receptor-1 expression is associated with neointimal formation in vitro. Am J Pathol 148, 1193 - 1202 (1996)

15 Yamawaki H, Sato K, Hori M, Ozaki H, Nakamura S, Nakayama $\mathrm{H}$, Doi $\mathrm{K}$ and Karaki H: Impairment of EDR by a long-term PDGF treatment in organ-cultured rabbit mesenteric artery. Am J Physiol 277, H318 - H323 (1999)

16 Xue C and Johns RA: Endothelial nitric oxide synthase in the lungs of patients with pulmonary hypertension. N Engl J Med 333, 1642 - 1644 (1995)

17 Giaid A and Saleh D: Reduced expression of endothelial nitric oxide synthase in the lungs of patients with pulmonary hypertension. N Engl J Med 333, 214 - 221 (1995)

18 Shaul PW, Wells LB and Horning KM: Acute and prolonged hypoxia attenuate endothelial nitric oxide production in rat pulmonary arteries by different mechanisms. J Cardiovasc Pharmacol 22, 819 - 827 (1993)

19 Murata T, Yamawaki H, Hori M, Sato K, Ozaki H and Karaki H: Hypoxia impairs endothelium-dependent relaxation in organ cultured pulmonary artery. Eur J Pharmacol 421, 45 - 53 (2001)

20 Havenga MJ, Lemckert AA, Grimbergen JM, Vogels R, Huisman LG, Valerio D, Bout A and Quax PH: Improved adenovirus 
vectors for infection of cardiovascular tissues. J Virol 75, 3335 - 3342 (2001)

21 Yao A and Wang DH: Heterogeneity of adenovirus-mediated gene transfer in cultured thoracic aorta and renal artery of rats. Hypertension 26, 1046 - 1050 (1995)

22 Rekhter MD, Simari RD, Work CW, Nabel GJ, Nabel EG and Gordon D: Gene transfer into normal and atherosclerotic human blood vessels. Circ Res 82, 1243 - 1252 (1998)

23 George SJ, Baker AH, Angelini GD and Newby AC: Gene transfer of tissue inhibitor of metalloproteinase-2 inhibits metalloproteinase activity and neointima formation in human saphenous veins. Gene Ther 5, $1552-1560$ (1998)

24 George SJ, Johnson JL, Angelini GD, Newby AC and Baker AH: Adenovirus-mediated gene transfer of the human TIMP-1 gene inhibits smooth muscle cell migration and neointimal formation in human saphenous vein. Hum Gene Ther 9, $867-$ 877 (1998)

25 Cowan KN, Jones PL and Rabinovitch M: Elastase and matrix metalloproteinase inhibitors induce regression, and tenascin- $\mathrm{C}$ antisense prevents progression, of vascular disease. J Clin Invest 105, $21-34$ (2000)

26 Cowan KN, Heilbut A, Humpl T, Lam C, Ito S and Rabinovitch $\mathrm{M}$ : Complete reversal of fatal pulmonary hypertension in rats by a serine elastase inhibitor. Nat Med 6, $698-702$ (2000)

27 Fisslthaler B, Fleming I and Busse R: EDHF: a cytochrome P450 metabolite in coronary arteries. Semin Perinatol 24, 15-19 (2000)

28 Bolz SS, Fisslthaler B, Pieperhoff S, De Wit C, Fleming I, Busse $\mathrm{R}$ and Pohl $\mathrm{U}$ : Antisense oligonucleotides against cytochrome P450 2C8 attenuate EDHF- mediated $\mathrm{Ca}^{2+}$ changes and dilation in isolated resistance arteries. FASED J 14, 255 - 260 (2000)

29 Earley JJ, Su X and Moreland RS: Caldesmon inhibits active crossbridges in unstimulated vascular smooth muscle: an antisense oligodeoxynucleotide approach. Circ Res 83, 661-667 (1998)

30 Yoshimoto R, Hori M, Takahashi K, Taniguchi SI, Katsuki M, Ozaki $\mathrm{H}$ and Karaki $\mathrm{H}$ : $\mathrm{Ca}^{2+}$-sensitization of contraction in the h1 calponin-deficient smooth muscle. Jpn J Pharmacol 84, $474-475(2000)$

31 Takahashi K, Yoshimoto R, Fuchibe K, Fujishige A, MitsuiSaito M, Hori M, Ozaki H, Yamamura H, Awata N, Taniguchi S, Katsuki M, Tsuchiya $\mathrm{T}$ and Karaki H: Regulation of shortening velocity by calponin in intact contracting smooth muscles. Biochem Biophys Res Commun 279, 150 - 157 (2000)

32 Je HD, Gangopadhyay SS, Ashworth TD and Morgan KG: Calponin is required for agonist-induced signal transductionevidence from an antisense approach in ferret smooth muscle. J Physiol (Lond) 537, 567 - 577 (2001)

33 Tang DD and Gunst SJ: Depletion of focal adhesion kinase by antisense depresses contractile activation of smooth muscle. Am J Physiol 280, C874 - C883 (2001)

34 Tang D, Mehta D and Gunst SJ: Mechanosensitive tyrosine phosphorylation of paxillin and focal adhesion kinase in tracheal smooth muscle. Am J Physiol 276, C250 - C258 (1999)

35 Folkow B: Physiological aspects of primary hypertension. Physiol Rev 62, 347 - 504 (1982)

36 Owens GK and Schwartz SM: Vascular smooth muscle cell hypertrophy and hyperploidy in the Goldblatt hypertensive rat. Circ Res 53, 491 - 501 (1983)

37 Owens GK: Influence of blood pressure on development of aortic medial smooth muscle hypertrophy in spontaneously hypertensive rats. Hypertension 9, 178 - 187 (1987)

38 Birukov KG, Bardy N, Lehoux S, Merval R, Shirinsky VP and Tedgui A: Intraluminal pressure is essential for the maintenance of smooth muscle caldesmon and filamin content in aortic organ culture. Arterioscler Thromb Vasc Biol 18, 922 - 927 (1998)

39 Adam LP, Franklin MT, Raff GJ and Hathaway DR: Activation of mitogen-activated protein kinase in porcine carotid arteries. Circ Res 76, 183 - 190 (1995)

40 Birukov KG, Lehoux S, Birukova AA, Merval R, Tkachuk VA and Tedgui $\mathrm{A}$ : Increased pressure induces sustained protein kinase $\mathrm{C}$-independent herbimycin A-sensitive activation of extracellular signal-related kinase $1 / 2$ in the rabbit aorta in organ culture. Circ Res 81, 895 - 903 (1997)

41 Zeidan A, Nordstrom I, Dreja K, Malmqvist U and Hellstrand P: Stretch-dependent modulation of contractility and growth in smooth muscle of rat portal vein. Circ Res 87, 228 - 234 (2000)

42 Bishop-Bailey D, Larkin SW, Warner TD, Chen G and Mitchell JA: Characterization of the induction of nitric oxide synthase and cyclo-oxygenase in rat aorta in organ culture. Br J Pharmacol 121, 125 - 133 (1997)

43 Hori M, Kita M, Torihashi S, Miyamoto S, Won KJ, Sato K, Ozaki H and Karaki H: Upregulation of iNOS by COX-2 in muscularis resident macrophage of rat intestine stimulated with LPS. Am J Physiol 280, G930 - G938 (2001)

44 Takizawa $\mathrm{S}$, Ozaki $\mathrm{H}$ and Karaki $\mathrm{H}$ : Interleukin- $1 \beta$-induced, nitric oxide-dependent and -independent inhibition of vascular smooth muscle contraction. Eur J Pharmacol 330, 143-150 (1997)

45 Kauser K, Sonnenberg D, Diel P and Rubanyi GM: Effect of $17 \beta$-oestradiol on cytokine-induced nitric oxide production in rat isolated aorta. Br J Pharmacol 123, 1089 - 1096 (1998)

46 Hayashi T, Yamada K, Esaki T, Mutoh E and Iguchi A: Effect of estrogen on isoforms of nitric oxide synthase: possible mechanism of anti-atherosclerotic effect of estrogen. Gerontology 43, 24 - 34 (1997)

47 Binko $\mathrm{J}$ and Majewski $\mathrm{H}$ : $17 \beta$-Estradiol reduces vasoconstriction in endothelium-denuded rat aortas through inducible NOS. Am J Physiol 274, H853 - H859 (1998)

48 Murata T, Yamawaki H, Hori M, Sato K, Ozaki H and Karaki H: Chronic vascular toxicity of doxorubicin in an organ-cultured artery. Br J Pharmacol 132, 1365 - 1373 (2001)

49 Murata T, Yamawaki H, Yoshimoto R, Hori M, Sato K, Ozaki H and Karaki H: Chronic effect of doxorubicin on vascular endothelium assessed by organ culture study. Life Sci 69, $2685-$ 2695 (2001)

50 Ward SM, Harney SC, Bayguinov JR, McLaren GJ and Sanders KM: Development of electrical rhythmicity in the murine gastrointestinal tract is specifically encoded in the tunica muscularis. J Physiol (Lond) 505, 241 - 258 (1997)

51 Miettinen PJ, Berger JE, Meneses J, Phung Y, Pedersen RA, Werb $\mathrm{Z}$ and Derynck R: Epithelial immaturity and multiorgan failure in mice lacking epidermal growth factor receptor. Nature 376, 337 - 341 (1995)

52 Duh G, Mouri N, Warburton D and Thomas DW: EGF regulates early embryonic mouse gut development in chemically defined organ culture. Pediatr Res 48, $794-802$ (2000)

53 Canning BJ, Undem BJ, Karakousis PC and Dey RD: Effects of organotypic culture on parasympathetic innervation of guinea pig trachealis. Am J Physiol 271, L698 - L706 (1996) 